\title{
A prospective cross-over study to evaluate the effect of two different occlusal concepts on the masseter muscle activity in implant-retained mandibular overdentures
}

\author{
Ahmed M. Abdelhamid ${ }^{1}$, Kenda I. Hanno ${ }^{2^{*}}$ and Mohamed H. Imam
}

\begin{abstract}
Background: The purpose of this prospective cross-over study is to evaluate the effect of bilateral balanced occlusion and canine guidance occlusion on the masseter muscle activity using implant-retained mandibular overdentures.

Methods: After evaluation of 12 completely edentulous patients using cone beam computed tomography (CBCT), mucoperiosteal flaps were reflected exposing the mandibular interforaminal region. Two implants were placed in the interforaminal region for each of the 12 patients. After a healing period of 3 months, acrylic maxillary complete dentures and mandibular overdentures were fabricated with bilateral balanced occlusion for 6 patients and canine guidance occlusion for the other 6 patients. Electromyographic evaluation of the masseter muscles, during clenching on a silicon index and chewing peanuts and cake, was conducted on the patients after using their dentures for 4 weeks. Each occlusion concept was then converted into the other concept using the same dentures, and the procedure of evaluation was repeated after 4 weeks. The recordings were analyzed statistically using Wilcoxon signed ranks test. $p<0.05$ was considered statistically significant.

Results: The highest electromyographic activity of the masseter muscles was recorded during clenching on a preformed silicon index followed by chewing peanut then cake for both occlusal concepts. The recordings of the masseter muscle associated with canine guidance occlusion were higher than bilateral balanced occlusion but with no statistically significant difference except between the right masseter muscles during clenching $\left(p=0.042^{*}\right)$.

Conclusions: Both bilateral balanced occlusion and canine guidance occlusion can be used successfully in implant-retained mandibular overdentures without affecting masseter muscle activity.
\end{abstract}

Keywords: Balanced occlusion, Canine guidance, Electromyography, Implant-retained overdentures, Muscle activity

\section{Background}

Treatment of edentulous patients using a conventional complete removable denture is a common clinical undertaking. However, those patients may experience problems which include pain during mastication, reduced masticatory ability, as well as insufficient stability and retention of the mandibular denture [1].

The introduction of dental implants and, subsequently, the implant-supported mandibular overdenture has

\footnotetext{
* Correspondence: kendahanno@gmail.com

${ }^{2}$ Prosthodontics, Faculty of Dentistry, Alexandria University, Alexandria, Egypt Full list of author information is available at the end of the article
}

improved the quality of life for edentulous patients [2]. The biomechanical aspects of occlusal design, configuration, and anatomy significantly influence the ultimate success of implant. The development of occlusal concepts that is in harmony with the rest of the stomatognathic system is a major contributing factor in the long-term success rate of the implant-supported prosthesis [3].

Many authors [4] emphasized the role of occlusion as a key factor in implant success. James [5] stated that "nearly all problems of the implants that develop between the first and sixth week post-insertion are directly related to the occlusion." Lindquist et al., [6] and Miyata et al., [7] 
studied the longitudinal effects of occlusal forces on osseointegrated implants and found that overloading was the main cause for bone loss around fixtures and/or loss of osseointegration of successfully integrated implants. The prosthesis must therefore be fabricated as accurately as possible in order to achieve long-term success, and occlusion should be a key factor of the overall success rate.

Currently, the occlusal philosophies that are proposed for implant overdentures are based on those for conventional complete dentures [8]. These philosophies include bilateral balanced occlusion and lingualized occlusion.

Balanced occlusion concept has been recommended in removable implant overdentures especially for patients with complete maxillary denture and mandibular implantretained overdentures to distribute the loads and to provide better stability [9]. The chewing forces are applied to the working and balancing sides simultaneously and over all of the surfaces of the edentulous ridge, resulting in the decrease in pressure on the edentulous jaw and preventing residual ridge reduction [10].

For more than a hundred years, textbooks and undergraduate teaching have stated that canine guided dentures should be avoided, since they would result in denture instability and impaired muscle function; however, recent research has shown that conventional complete dentures can function successfully without balanced occlusion [11].

Canine guidance disengages the posterior teeth during excursive mandibular movements by vertically and horizontally overlapping the canines [12]. Grubwieser et al., [13] stated that canine guidance occlusion (CGO) can be used successfully in complete dentures as it improves mandibular denture retention, esthetic appearance, and masticatory ability. They also observed that CGO reduced muscle activity during lateral movement and protrusion when compared with $\mathrm{BBO}$.

Canine guidance is easier and faster to be provided. It seems to be rational to recommend this occlusal concept for the excursive movements of the mandible in complete dentures wearers until future research can solve this question [14].

The various methods for assessment of masticatory function include food particle size estimation [15], sieving method [16], colorimetric determination [17], optical scanning method [18], biting force [15], and weight loss of viscoelastic food [19].

Occlusion may alter muscle activity and related jaw movements in mastication. Muscle activity, which is a reflection of masticatory function of the patient, can be objectively evaluated using surface electromyography (EMG) [20]. EMG is a valuable parameter to assess muscular dysfunction. Surface EMG measures muscle activity noninvasively using surface electrodes placed on the skin overlying the muscle to determine the timing of the muscle contraction and to investigate the behavior of the muscle during functions of the stomatognathic system [21].

Aziz et al., (2008) compared the effect of two different occlusal schemes on the muscle activity in implantsupported mandibular overdentures using electromyography. The results revealed slight increase in the muscle activity in patients rehabilitated with dentures constructed following the lingualized concept of occlusion compared to dentures constructed following the monoplane concept of occlusion [22].

The choice of an occlusal design or configuration for implant-retained prosthesis is broad and often controversial. To date, there is no evidence to recommend a specific occlusal design for implant-retained overdentures. No sufficient scientific evidence was found on applying canine guidance in implant-retained overdentures. Therefore, this study was conducted to investigate the effects of balanced occlusion and canine guidance on masseter muscle activity in implant-retained overdentures.

\section{Methods}

The study design is a prospective cross-over study.

Twelve completely edentulous patients aged $45-65$ years, having acceptable maxillomandibular relationship, sufficient inter-ridge space, and with no previous denture experience, were selected for this study. Complete maxillary and mandibular dentures were fabricated for each patient.

Since the type of opposing occlusion is a critical factor that influences the magnitude of forces transmitted to the implant bone interface, the opposing occlusion was selected to be mucosa-supported complete denture. This was done to standardize and control the amount of occlusal forces applied to the abutments. Complete dentures were proved to exert less amount of force compared to the natural teeth [23].

The selection of the interforaminal area of the mandible, where two implants were placed, was based on the recommendation by Lekholm and Zarb [24] and Hong et al., [25] as the bone in this area is of good quality. Implants are demonstrated to have fewer micro-movements, increased initial stability, and reduced stress concentration in high-quality bone [26]. Furthermore, it has been established that the survival of the root form titanium implants is very high in the anterior mandible and that the incidence of surgical complications is very low $[27,28]$.

A clear acrylic radiographic/surgical mandibular template including gutta-percha radiopaque indicators allowed implant alignment along planned prosthetic axes during implant surgery and ensured good visual access [29].

The previously fabricated denture was duplicated in clear acrylic resin and used as a radiographic surgical guide using gutta-percha as radiopaque markers. Each 


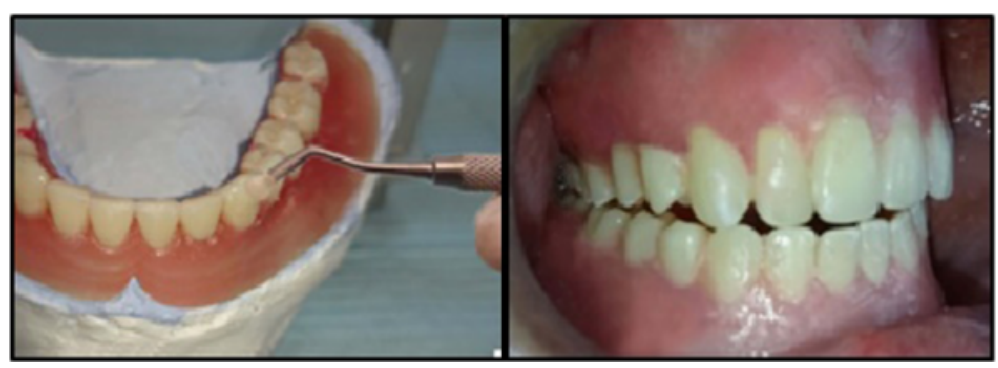

Fig. 1 Application of light-cure composite resin on the mandibular canines and a view of canine guidance occlusion intraorally

patient was evaluated radiographically using cone beam computed tomography (CBCT) before surgical implant placement. A mucoperiosteal flap was reflected exposing the mandibular interforaminal region for optimal implant placement. Two implants (Dentium Superline, Dentium Co. Ltd., Korea) were screwed in position. The length of the implants was $10 \mathrm{~mm}$ and the diameter is $3.6 \mathrm{~mm}$.

After a healing period of 3 months, acrylic maxillary and mandibular overdentures were fabricated with bilateral balanced occlusion for all patients. Positioner attachments were used and incorporated into the dentures using direct pickup method. Six patients used their dentures with bilateral balanced occlusion for 4 weeks then were evaluated by EMG. Following evaluation, it was converted into canine guidance occlusion using the same denture. This was achieved clinically by remounting using the semi-adjustable articulator.

Light-cured composite resin was then added in the mandibular canines to provide an interarch disocclusion space of $2 \mathrm{~mm}$ during eccentric movements.

For the other six patients, canine guidance occlusion was applied first in the try-in stage through application of light-cure composite resin on the mandibular canines (Fig. 1).

The patients used their dentures for 4 weeks then were evaluated using EMG. After evaluation, canine guidance occlusion was converted into bilateral balanced occlusion by removal of the composite resin from the mandibular canines (Fig. 2). The positioner attachments (positioner abutment and socket set, Dentium Co.Ltd, Korea) were placed on the implants and attached to the dentures by direct pickup method (Fig. 3).

\section{Recording the electromyographic activity}

EMG has also been used to assess the masticatory function of mandibular implant-retained overdentures. The electrical output of a muscle, measured by electromyography, is proportional to the energy consumed to produce contractions. The masseter and anterior temporalis muscles on both sides were evaluated because they are the largest and strongest of the masticatory muscles, the most superficial and are accessible to surface EMG examination. The surface EMG recordings provided a safe, easy, and noninvasive method that allowed objective quantification of the energy of the muscle [30].

Standard amounts and sizes of cake and peanuts were used to reduce patient variability. These test foods were an example of soft and hard food, respectively, and they gave an idea about the effect of different types of food on muscle activity during function. Preformed silicon index was used to measure the muscle activity during clenching [31].

Evaluation of muscle activity was performed by measuring activity of the masseter muscles on both sides for both occlusal concepts at the end of 2 weeks using electromyography (Nicolet VikingQuest version 11, USA) with three types of test foods.

During all recordings, the patients were seated with their head unsupported and were asked to maintain a naturally erect position. The masseteric myoelectric activity of both sides (right and left) were recorded by means of disposable bipolar electrodes positioned on the bellies of the muscles parallel to the fiber orientation (Fig. 4).

Electroconductive gel was applied on the electrodes before they contacted the skin. The recording electrodes

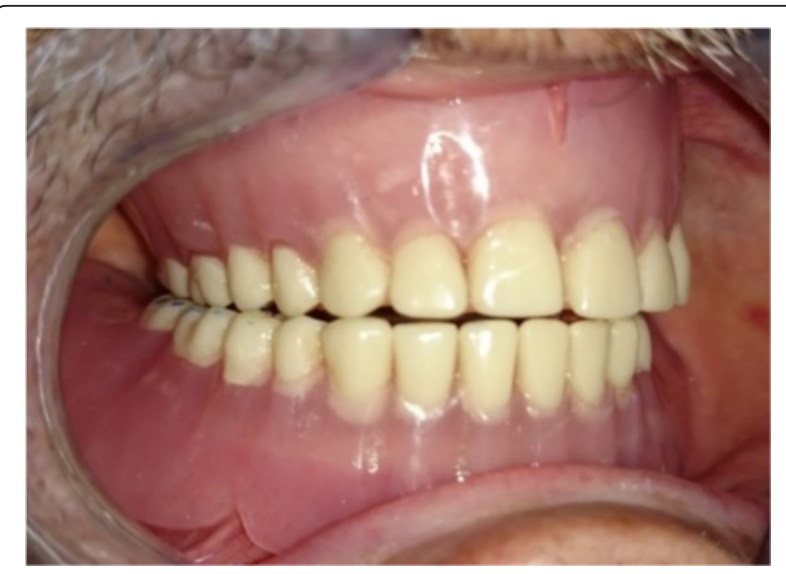

Fig. 2 Bilateral balanced occlusion intraorally 


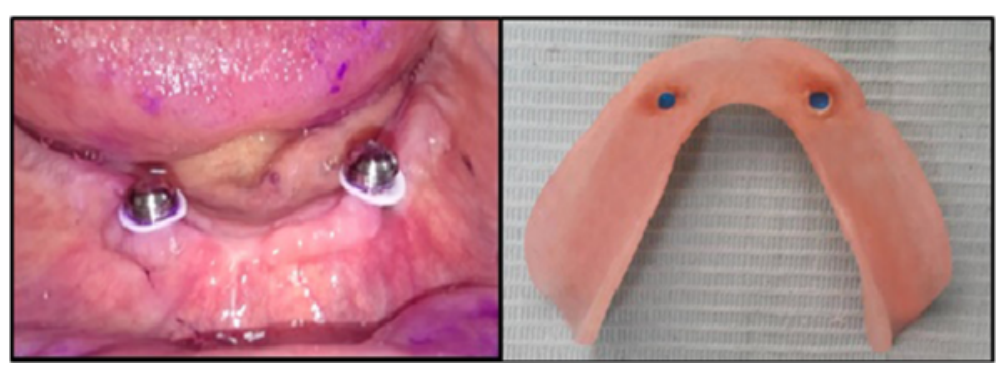

Fig. 3 The white blockout spacers in place with the locator caps on top and the positioner socket with blue nylon cap

were positioned approximately $20 \mathrm{~mm}$ apart. The patient was grounded by using a grounding electrode. The third electrode was fixed on the palm of the patient's hand.

Each patient was instructed to clench with a preformed silicon index made by using vinyl polysiloxane material (putty) of standardized size positioned at the premolar region for $30 \mathrm{~s}$ to measure the muscle activity during clenching. Then the patients were instructed to chew on one peanut of similar size and diameter, and the EMG was recorded. Then the patients were instructed to chew on a piece of cake of standardized size $(2 \mathrm{~cm} \times 2 \mathrm{~cm})$, and the EMG was recorded. The patients chewed the test samples on the right and left sides at 10-s intervals using their arbitrary chewing frequency until they are ready to swallow before the EMG was recorded.

At the end of the record and before removing the surface electrodes, the positions of the electrodes were marked to be used as a guide for accurate reproducibility. The previous tasks were separated by a recovery rest

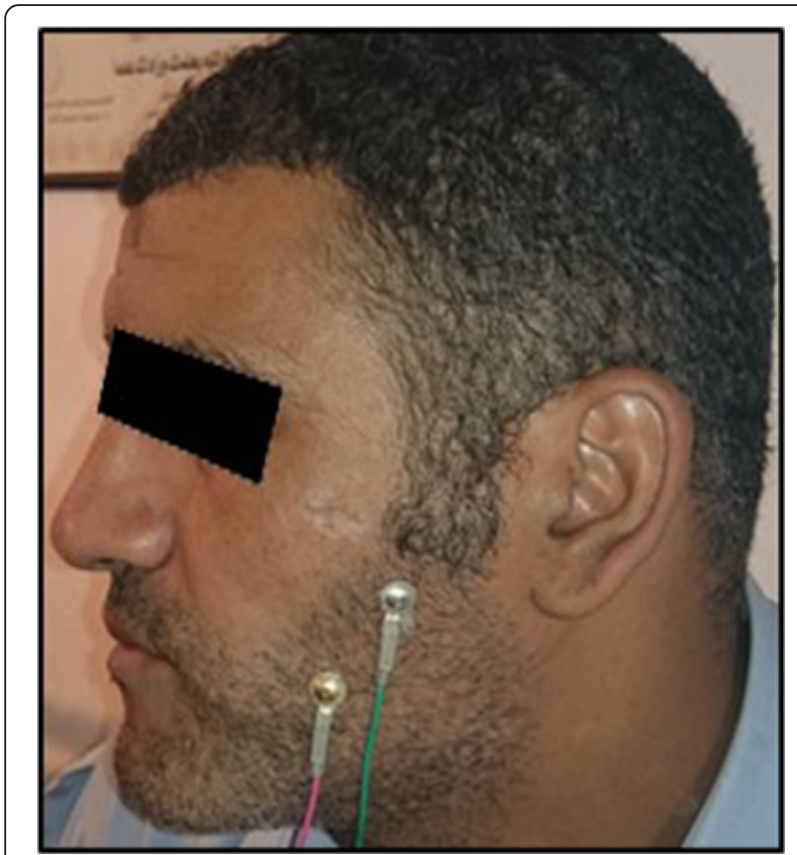

Fig. 4 Bipolar electrodes positioned at the masseter muscle belly period of $2 \mathrm{~min}$. The computerized data showed the root mean square (RMS) of the EMG signals (Fig. 5).

\section{Statistical analysis}

Data were fed to the computer. Quantitative data were described using range (minimum and maximum), mean, standard deviation, and median. Wilcoxon signed ranks test was applied. Significance of the obtained results was judged at the $5 \%$ level. A $p$ value less than 0.05 was considered statistically significant.

\section{Ethical approval}

This study protocol was approved by the research ethics committee of the Faculty of Dentistry, Alexandria University, Egypt.

\section{Ethics, consent, and permissions}

All the patients signed an informed consent form before participation in this study.

\section{Consent to publish}

All the patients who participated in the study provided consent to publish the data obtained from them during the study.

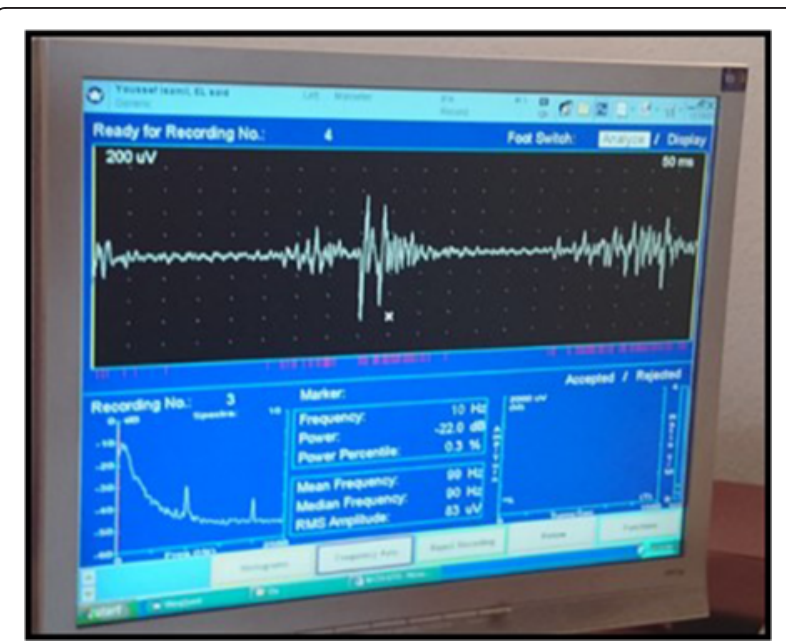

Fig. 5 EMG signal on the monitor of the computer 


\section{Results}

In the right masseter muscle, bilateral balanced occlusion has shown lower RMS values on clenching with the silicon index, chewing peanut, and chewing cake compared to the RMS values of canine guidance occlusion (Table 1).

However, the table shows no statistically significant difference between the two occlusal concepts for the right masseter muscle. The difference was statistically significant only during clenching on a silicon index $\left(p=0.042^{*}\right)$.

In the left masseter muscle, bilateral balanced occlusion has shown lower RMS values on clenching with the silicon index, chewing peanut, and chewing cake compared to the RMS values of canine guidance occlusion. The table shows no statistically significant difference between the two occlusal concepts for the left masseter muscle (Table 1).

In the right masseter muscle, clenching on silicon index showed the highest RMS values followed by chewing peanut, and the least RMS value was for chewing cake. The results showed a statistical significant difference between them $(p=0.006)$.

In the left masseter muscle, clenching on silicon index showed the highest RMS values followed by chewing peanut and the least RMS value was for chewing cake. The results showed no statistical significant difference between them $(p=0.082)$. There was a statistical significant difference between clenching on silicon index and chewing cake $\left(p_{1}=0.037^{*}\right)$ (Table 2$)$.

In the right masseter muscle, clenching on silicon index showed the highest RMS values followed by chewing peanut and the least RMS value was for chewing cake. The results showed no statistical significant difference between them $(p=0.778)$.

In the left masseter muscle, clenching on silicon index showed the highest RMS values followed by chewing peanut, and the least RMS value was for chewing cake

Table 1 Comparison between bilateral balanced occlusion and canine guidance occlusion according to EMG signals (RMS values) of the masseter muscle

\begin{tabular}{|c|c|c|c|c|}
\hline \multirow{2}{*}{ Food type } & \multicolumn{2}{|c|}{$\begin{array}{l}\text { Bilateral Balanced Occlusion } \\
\qquad(\mathrm{n}=12)\end{array}$} & \multicolumn{2}{|c|}{$\begin{array}{l}\text { Canine Guidance Occlusion } \\
\qquad(\mathrm{n}=12)\end{array}$} \\
\hline & Right & Left & Right & Left \\
\hline \multicolumn{5}{|l|}{ Silicon index } \\
\hline Min. - Max. & $26.0-66.0$ & $33.0-78.0$ & $29.0-289.0$ & $11.0-150.0$ \\
\hline Mean \pm SD & $55.75 \pm 13.05$ & $62.17 \pm 15.86$ & $61.67 \pm 72.14$ & $68.75 \pm 42.86$ \\
\hline Median & 60.0 & 64.50 & 43.0 & 69.0 \\
\hline$Z(p)$ & & $\begin{array}{r}2.032 *(0.042 *) \\
\longrightarrow\end{array}$ & \multicolumn{2}{|l|}{$0.347(0.728)$} \\
\hline \multicolumn{5}{|l|}{ Peanut } \\
\hline Min. - Max. & $28.0-63.0$ & $21.0-108.0$ & $34.0-185.0$ & $24.0-126.0$ \\
\hline Mean \pm SD & $45.67 \pm 12.34$ & $57.33 \pm 28.65$ & $55.08 \pm 41.27$ & $61.50 \pm 26.21$ \\
\hline Median & 43.50 & 50.50 & 44.0 & 62.0 \\
\hline$Z$ (p) & & $\stackrel{0.116(0.908)}{\longrightarrow}$ & $\leftarrow 0.753(0.452)$ & $\leftarrow$ \\
\hline \multicolumn{5}{|l|}{ Cake } \\
\hline Min. - Max. & $28.0-54.0$ & $23.0-85.0$ & $21.0-87.0$ & $29.0-143.0$ \\
\hline Mean \pm SD. & $38.33 \pm 8.24$ & $42.50 \pm 21.66$ & $46.83 \pm 20.70$ & $54.75 \pm 31.19$ \\
\hline Median & 37.50 & 40.50 & 39.0 & 51.50 \\
\hline$Z$ (p) & & $0.696(0.487)$ & $1.159(0.246)$ & \\
\hline
\end{tabular}


Table 2 Comparison between the different test foods according to RMS values of the EMG signals of right and left masseter muscles in bilateral balanced occlusion

\begin{tabular}{|c|c|c|c|c|c|}
\hline & Silicon index $(n=12)$ & Peanut $(n=12)$ & Cake $(n=12)$ & ${ }^{\mathrm{kW}} \mathrm{X}^{2}$ & $p$ \\
\hline \multicolumn{6}{|l|}{ Right } \\
\hline Min.-Max. & $26.0-66.0$ & $28.0-63.0$ & $28.0-54.0$ & & \\
\hline Mean \pm SD & $55.75 \pm 13.05$ & $45.67 \pm 12.34$ & $38.33 \pm 8.24$ & $10.180^{*}$ & $0.006^{*}$ \\
\hline \multirow[t]{2}{*}{ Median } & 60.0 & 43.50 & 37.50 & & \\
\hline & \multicolumn{5}{|c|}{$p_{1}=0.005^{*}, p_{2}=0.037^{*}, p_{3}=0.063$} \\
\hline \multicolumn{6}{|l|}{ Left } \\
\hline Min.-Max. & $33.0-78.0$ & $21.0-108.0$ & $23.0-85.0$ & & \\
\hline Mean \pm SD & $62.17 \pm 15.86$ & $57.33 \pm 28.65$ & $42.50 \pm 21.66$ & 5.013 & 0.082 \\
\hline \multirow[t]{2}{*}{ Median } & 64.50 & 50.50 & 40.50 & & \\
\hline & \multicolumn{5}{|c|}{$p_{1}=0.037^{*}, p_{2}=0.354, p_{3}=0.131$} \\
\hline
\end{tabular}

${ }^{k W} X^{2}$ chi square for Kruskal-Wallis test, $p_{1} p$ value for Mann-Whitney test for comparing between Silicon index and Cake, $p_{2} p$ value for Mann-Whitney test for comparing between silicon index and peanut, $p_{3} p$ value for Mann-Whitney test for comparing between cake and peanut *Statistically significant at $p \leq 0.05$

$(54.75 \pm 31.19)$. The results should no statistical significant difference between them $(p=0.344)$. (Table 3)

\section{Discussion}

Many authors stated that bilateral balanced occlusion promotes better masticatory efficiency by bringing a larger amount of grinding surfaces into contact at each movement $[32,33]$. The results of the current study did not show a significant difference for muscle function by EMG between the studied occlusal concepts. This finding coincides with El-Okel who compared masticatory efficiency through evaluation of electromyographic activity between bilateral balanced occlusion, canine guidance occlusion, lingualized, and monoplane occlusion schemes and found no significant difference [34]. The results also coincide with Grunert et al., [20] who found no difference in muscle activity between bilateral balanced occlusion and canine guidance occlusion in complete dentures. These results were also similar to Neto AF et al., who stated that bilateral balanced occlusion did not improve masticatory efficiency when compared with canine guidance [11]. Abd Elmonem evaluated masticatory efficiency in complete denture wearers with bilateral balanced occlusion and canine guidance using the colorimetric method and also found no statistical significant difference between them [35].

Despite the insignificant difference between EMG activity of the masseter muscles in bilateral balanced occlusion and canine guidance occlusion, the mean EMG activity was higher in canine guidance compared to bilateral balanced occlusion. This could be due to larger amount of grinding surfaces brought into contact at each movement in balanced occlusion resulting in less effort needed by the muscles during chewing. This could

Table 3 Comparison between the different test foods according to RMS values of the EMG signals of right and left masseter muscles in canine guidance occlusion

\begin{tabular}{|c|c|c|c|c|c|}
\hline & Silicon index $(n=12)$ & Peanut $(n=12)$ & Cake $(n=12)$ & ${ }^{k W} x^{2}$ & $p$ \\
\hline \multicolumn{6}{|l|}{ Right } \\
\hline Min.-Max. & $29.0-289.0$ & $34.0-185.0$ & $21.0-87.0$ & & \\
\hline Mean \pm SD & $61.67 \pm 72.14$ & $55.08 \pm 41.27$ & $46.83 \pm 20.70$ & 0.501 & 0.778 \\
\hline \multirow[t]{2}{*}{ Median } & 43.0 & 44.0 & 39.0 & & \\
\hline & \multicolumn{3}{|c|}{$p_{1}=1.000, p_{2}=0.488, p_{3}=0.602$} & & \\
\hline \multicolumn{6}{|l|}{ Left } \\
\hline Min.-Max. & $11.0-150.0$ & $24.0-126.0$ & $29.0-143.0$ & & \\
\hline Mean \pm SD & $68.75 \pm 42.86$ & $61.50 \pm 26.21$ & $54.75 \pm 31.19$ & 2.134 & 0.344 \\
\hline \multirow[t]{2}{*}{ Median } & 69.0 & 62.0 & 51.50 & & \\
\hline & \multicolumn{3}{|c|}{$p_{1}=0.225, p_{2}=0.728, p_{3}=0.202$} & & \\
\hline
\end{tabular}

${ }^{K W} X^{2}$ chi square for Kruskal-Wallis test, $p_{1} p$ value for Mann-Whitney test for comparing between silicon index and cake, $p_{2} p$ value for Mann-Whitney test for comparing between silicon index and peanut, $p_{3} p$ value for Mann-Whitney test for comparing between cake and peanut

*Statistically significant at $p \leq 0.05$ 
also be due to bilateral balanced occlusion facilitating adaptation to the new denture as stated by Rehmann et al. [36]. These results are in contrast with Grubweiser et al., [13] and Miralles et al., [37] who found that canine guidance occlusion reduced masseter muscle activity in complete denture wearers. They stated that neuromuscular function in edentulous subjects is similar to that found in dentate people and that canine guided dentures prevent parafunctional habits.

The results of this study showed that the EMG activity of the masseter muscles during clenching on a preformed silicon index was significantly higher than during chewing peanut and chewing cake. This finding is in line with Miralles et al., [37] who pointed out that the increased EMG activity may be due to increased vertical dimension leading to increased muscle activity during maximum voluntary clenching. This finding is also in line with Darwish et al., [38]. The results also show higher mean EMG activity when chewing peanut than when chewing cake in this study. This coincides with van der Bilt et al., [39] who stated that harder food consistency required higher muscle activity levels due to higher muscle force needed to comminute hard food. The results are also in agreement with Karkazis [40] who found that harder foods required higher chewing rates, higher electrical activity of the masseter muscle, and higher relative contraction periods, accompanied by shorter cycle durations.

\section{Limitations of the study}

These include short follow-up periods, no subjective assessment of the dentures with different occlusion concepts using questionnaires and depending entirely on electromyography for the assessment of masticatory function.

\section{Conclusions}

Within the limitations of this study of short follow-up periods of mandibular implant-retained overdenture and maxillary complete denture, the results lead to that both bilateral balanced occlusion and canine guidance occlusion can be used successfully in implant-retained overdentures without affecting masticatory function. However, the procedures involved in construction of dentures with bilateral balanced occlusion are more complex and time consuming. Greater muscle activity of both muscles is shown when chewing hard food due to higher muscle force needed to comminute hard food compared to soft food.

\section{Recommendations}

The present study recommends the following:

- Further investigations for a longer follow-up period and for a larger sample to confirm widespread use of canine guidance occlusal concept and involving subjective assessment using questionnaires for the patients' satisfaction

- Evaluation of the effect of different attachment types on masticatory function using the canine guidance concept in implant-retained overdentures

- Evaluation of canine guidance occlusal concept using a different method of evaluation of masticatory function other than electromyography

\section{Abbreviations}

BBO: Bilateral Balanced Occlusion; CBCT: Cone Beam Computed Tomography; CGO: Canine Guidance Occlusion; EMG: Electromyography; ME: Masticatory Efficiency.

\section{Competing interests}

The authors Prof. Dr. Ahmed Mohamed Abdelhamid, Kenda Ibrahim Hisham Hanno, and Prof. Dr. Mohamed Hassan Imam state that they have no competing interests.

\section{Authors' contributions}

$\mathrm{KIH}$ performed all the clinical procedures of the research and writing of the research article. The clinical procedures involve selection of the patients, surgical placement of the dental implants, construction of the maxillary and mandibular complete dentures and overdentures, conversion of the occlusal concepts, and electromyographic evaluation twice for each patient using the three test samples. AMA supervised the clinical work and revised the intellectual content of the research article. MHI supplied the electromyography machine in his clinic to measure the activity of the masseter muscles and provided the sheets containing the EMG signals for each test sample for each patient. All authors read and approved the final manuscript.

\section{Acknowledgements}

I would like to express my sincere gratitude to my father, Dr. Ibrahim Hisham Hanno (pedodontist), who supplied all the materials used for the research and funded the research.

I would also like to express my deepest gratitude to my mother, Dr. Mervat M. Ghoneim (prosthodontist), for her continuous support and revision of both the prosthodontic clinical steps and intellectual content of the article.

\section{Author details}

${ }^{1}$ Prosthodontics Department, Faculty of Dentistry, Alexandria University, Alexandria, Egypt. ${ }^{2}$ Prosthodontics, Faculty of Dentistry, Alexandria University, Alexandria, Egypt. ${ }^{3}$ Physical Medicine, Rheumatology and Rehabilitation, Faculty of Medicine, Alexandria University, Alexandria, Egypt.

Received: 9 September 2015 Accepted: 9 December 2015

Published online: 22 December 2015

\section{References}

1. Al-Ghafli SA, Michalakis KX, Hirayama H, Kang K. The in vitro effect of different implant angulations and cyclic dislodgement on the retentive properties of an over denture attachment system. J Prosthet Dent. 2009;102:140-7.

2. Burns DR. Mandibular implant overdenture controversy-consensus and controversy. J Prosthod. 2000;90:45-58.

3. Skalak R. Biomechanical considerations in osseointegrated prostheses. J Prosthet Dent. 1983;49:843-8.

4. Branemark PI. Osseointegration and its experimental background. J Prosthet Dent. 1983;50:399-410.

5. James RA. Periodontal considerations in implant dentistry. J Prosthet Dent. 1973;30:202-9.

6. Lindquist LW, Rockler B, Carlson GE. Bone resorption and fixtures on edentulous patients treated with mandibular fixed tissue integrated prothesis. J Prosthet Dent. 1988;59:59-63.

7. Miyata T, Kobayashi Y, Araki H, Ohto T, Shin K. The influence of controlled occlusal overload on peri-implant tissue. Part 3: a histologic study in monkeys. Int J Oral Maxillofac Implants. 2000;15:425-31.

8. Kim Y, Oh TJ, Misch CE, Wang HL. Occlusal considerations in implant therapy: clinical guidelines with biomechanical rationale. Clin Oral Impl Res. 2005;16:26-35. 
9. Misch CE. Contemporary implant dentistry, $3^{\text {rd }}$ ed. Mosby Inc, St. Louis. 2008. pp: 38-67, 645-67.

10. Pera P, Bassi F, Schierano G, Appendino P, Preti G. Implant anchored complete mandibular denture: evaluation of masticatory efficiency, oral function and degree of satisfaction. J Oral Rehabil. 1998;25:462-7.

11. Farias Neto A, Mestriner Junior W, Carreiro AF. Masticatory efficiency in denture wearers with bilateral balanced occlusion and canine guidance. Braz Dent J. 2010;21:165-9.

12. Peroz I, Leuenberg A, Haustein I, Lange KP. Comparison between balanced occlusion and canine guidance in complete denture wearers-a clinical, randomized trial. Quintessence Int. 2003;34:607-12

13. Grubwieser G, Flatz A, Grunert I, Kofler M, Ulmer H, Gausch K, et al. Quantitative analysis of masseter and temporalis EMGs: a comparison of anterior guided versus balanced occlusal concepts in patients wearing complete dentures. J Oral Rehabil. 1999:26:731-6.

14. Farias-Neto A, Carreiro AF. Complete denture occlusion: an evidence-based approach. J Prosthodont. 2013;22:94-7.

15. Fontijn-Tekamp FA, Slagter AP, Van Der Bilt A, Hof MA V 'T, Witter DJ, Kalk W, et al. Biting and chewing in overdentures, full dentures, and natural dentitions. J Dent Res. 2000;79:1519-24.

16. Mowlana F, Heath MR, Van der Bilt A, Van der Glas HW. Assessment of chewing efficiency: a comparison of particle size distribution determined using optical scanning and sieving of almonds. J Oral Rehabil. 1994;21:545-51.

17. Santos CE, De Freitas O, Cesar A, Spadaro C, Mestriner-Junior W. Development of a colorimetric system for evaluation of masticatory efficiency. Braz Dent J. 2006:17:95-9.

18. Mowlana F, Heath R. Assessment of masticatory efficiency: new methods appropriate for clinical research in dental practice. Eur J Prosthodont Restor Dent. 1993;1:121-5.

19. Poyiadjis YM, Likeman PR. Some clinical investigations of the masticatory performance of complete denture wearers. J Dent. 1984;12:334-41.

20. Grunert I, Kofler M, Gausch K, Kronenberg M. Masseter and temporalis surface electromyography in patients wearing complete dentures comparing anterior and posterior occlusal concepts-a pilot study. J Oral Rehabil. 1994:21:337-47.

21. Miles TS, Nauntofte B, Svensson P. Clinical Oral Physiology. Copenhagen: Quintessence Publishing Co. Ltd; 2004. p. 214-5.

22. Aziz $\mathrm{H}$, El Afandy $\mathrm{M}$, Elsayed $\mathrm{M}$. The effect of occlusal design on muscle activity in implant supported mandibular overdentures. CDJ. 2008;2:335-50.

23. Reitz PV, Weiner MG, Levin B. An overdenture survey. J Prosthet Dent. 1980;43:457.

24. Lekholm U, Zarb G. Patient selection and preparation. In: Branemark PI, Zarb GA, Albrektsson T, editors. Tissue integrated prosthesis: osseointegration in clinical dentistry. Chicago: Quintessence; 1985. p. 199-209.

25. Hong HR, Pae A, Kim Y, Paek J, Kim HS, Kwon KR. Effect of implant position, angulation, and attachment height on peri-implant bone stress associated with mandibular two-implant overdentures: a finite element analysis. Int J Oral Maxillofac Implants. 2012;27:e69-76.

26. Kitagawa T, Tanimoto Y, Nemoto K, Aida M. Influence of cortical bone quality on stress distribution in bone around dental implant. Dent Mater J. 2005;24:219-24.

27. Karabuda C, Yaltirik M, Bayrakatar M. A clinical comparison of prosthetic complications of implant-supported over dentures with different attachment systems. Implant Dent. 2008;17:74-81.

28. Roe P. Kan JY, Rungcharassaeng K, Lozada JL. Immediate loading of unsplinted implants in the anterior mandible for overdentures: 3 -year results. Int J Oral Maxillofac Implants. 2011;26:1296-302.

29. Wulfman C, Hadida A, Rignon-Bret C. Radiographic and surgical guide fabrication for implant-retained mandibular overdenture. J Prosthet Dent. 2010;103:53-7.

30. Castroflorio T, Bracco P, Farina D. Surface electromyography in the assessment of jaw elevator muscles. J Oral Rehabil. 2008:35:638-45.

31. Uçankale M, Akoğlu B, Ozkan Y, Ozkan YK. The effect of different attachment systems with implant retained overdentures on maximum bite force and EMG. Gerodontology. 2012;29:24-9.

32. Zarb GA, Bolender CL, Eckert SE, Fenton AH, Jacob RF, Mericske-Stern R. Prosthodontic treatment for edentulous patients: complete dentures and implant-supported prostheses. 12th ed. St. Louis: Mosby; 2004. p. 294.

33. Ohguri T, Kawano F, Ichikawa T, Matsumoto N. Influence of occlusal scheme on the pressure distribution under a complete denture. Int J Prosthodont. 1999;12:353-8.
34. El-Okel AB. The effect of different occlusal schemes on the electromyographic activity and masticatory efficiency in complete denture wearers. Ph.D. Thesis. Department of Removable Prosthodontics, Faculty of Dentistry, Al-Azhar University. Egypt. 2006.

35. Abd Elmonem E. Colorimetric comparative analysis of masticatory efficiency in complete denture wearers with two different occlusal concepts. M.Sc. Thesis. Removable Prosthodontics Department, Faculty of Dentistry, Alexandria University. Egypt. 2014.

36. Rehmann P, Balkenhol M, Ferger P, Wostmann B. Influence of the occlusal concept of complete dentures on patient satisfaction in the initial phase after fitting: bilateral balanced occlusion versus canine guidance. Int $」$ Prosthodont. 2008;21:60-1.

37. Miralles R, Bull R, Manns A, Roman E. Influence of balanced occlusion and canine guidance on electromyographic activity of elevator muscles in complete denture wearers. J Prosthet Dent. 1989:61:494-8.

38. Darwish AA, Segaan LG, El Shorbagy ZA, Abd El Hamid AM. Electromyographic activity of masseter muscle of patients wearing complete dentures with different occlusal concepts. Alex Dent J. 1989;14:3.

39. van der Bilt A, van Kampen FMC, Cune MS. Masticatory function with mandibular implant-supported overdentures fitted with different attachment types. Eur J Oral Sci. 2006;114:191-6.

40. Karkazis HC. EMG activity of the masseter muscle in implant supported overdenture wearers during chewing of hard and soft food. J Oral Rehabil. 2002;29:986-91.

\section{Submit your manuscript to a SpringerOpen ${ }^{\circ}$ journal and benefit from:}

- Convenient online submission

- Rigorous peer review

- Immediate publication on acceptance

- Open access: articles freely available online

- High visibility within the field

- Retaining the copyright to your article

Submit your next manuscript at $\gg$ springeropen.com 